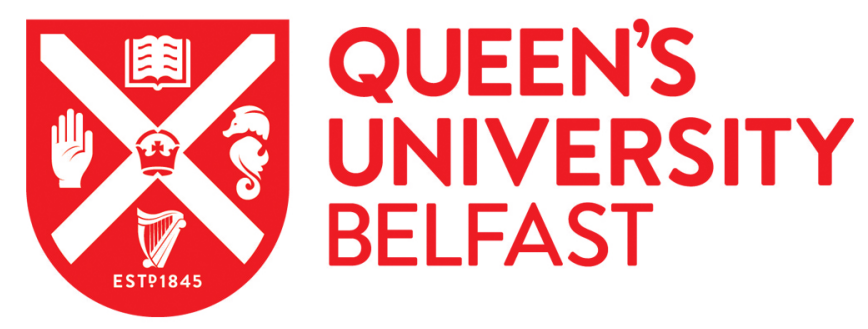

\title{
"I haven't read it, I've lived it!" The benefits and challenges of peer research with young people leaving care
}

Kelly, B., Friel, S., McShane, T., Pinkerton, J., \& Gilligan, E. (2020). "I haven't read it, I've lived it!" The benefits and challenges of peer research with young people leaving care. Qualitative Social Work, 19(1), 108-124. https://doi.org/10.1177/1473325018800370

Published in:

Qualitative Social Work

Document Version:

Peer reviewed version

Queen's University Belfast - Research Portal:

Link to publication record in Queen's University Belfast Research Portal

Publisher rights

(C) 2018 The Authors.

This work is made available online in accordance with the publisher's policies. Please refer to any applicable terms of use of the publisher.

\section{General rights}

Copyright for the publications made accessible via the Queen's University Belfast Research Portal is retained by the author(s) and / or other copyright owners and it is a condition of accessing these publications that users recognise and abide by the legal requirements associated with these rights.

Take down policy

The Research Portal is Queen's institutional repository that provides access to Queen's research output. Every effort has been made to ensure that content in the Research Portal does not infringe any person's rights, or applicable UK laws. If you discover content in the Research Portal that you believe breaches copyright or violates any law, please contact openaccess@qub.ac.uk. 


\title{
"I haven't read it, I've lived it!" The benefits and challenges of peer research with young people leaving care.
}

\begin{abstract}
Peer research is increasingly being used in research with children and young people. As a result there is a growing understanding of both the benefits and challenges of involving young peer researchers in qualitative research. This article aims to add to that understanding by providing a detailed account and reflection of the involvement of care leavers as peer researchers in the qualitative case study phase of a three year, mixed method study of the transitions of young people leaving care in Northern Ireland. It is one of only a few studies on leaving care in which peer research is central to the design. Particular attention is given to the benefits and challenges for all of the stakeholders involved in the research study: the participants, peer researchers, academic researchers and supporting partner organisation. Key learning points are identified and it is concluded that, despite the considerable challenges, peer research should become a routine consideration as a fruitful means of co-production in the design of care leaver research.
\end{abstract}

Key words: peer research; co-production; young people; leaving care

\section{Introduction}

In keeping with the recent policy emphasis on service user involvement in health and social care, there has been a growing interest in co-produced research (Boxall \& Beresford, 2013; Duffy et al., 2016). However, it is still questioned whether the additional resources and effort required to train and support children and young people to be peer researchers is sufficiently rewarded with additional value to the study (Holland et al., 2010; Lushey \& Munro, 2014). There are concerns that young peer researchers may undermine the validity and reliability of research interviews due to their lack of interview skills and their overuse of personal experience. However, proponents of peer research argue that with effective training, standardisation and appropriate levels of support it brings an 'insider' perspective to qualitative 
interviews that improves the validity and reliability of data. In this way, peer research can lead to more appropriate interview questions that reduce the risk of poor quality data or misinterpretation of responses (Smith et al., 2002). There is also a call for more reflexive approaches to co-production that value the unique contribution of both peer researchers and academics and that pays close attention to the impact of self on the research process (Berger, 2015; D’Cruz \& Gillingham, 2017; Tangvald-Pedersen \& Bongaardt, 2016).

The aim of this article is to contribute to this debate by reflecting on the benefits and challenges of peer research in a mixed method study of the transitions of care leavers with mental health and/or intellectual disabilities in Northern Ireland (Kelly et al., 2016). The study, known at the suggestion of a peer researcher as YOLO (You Only Leave Once), is one of only a few care leaver studies that has attempted to co-produce research with care experienced young people - or as one of the YOLO peer researchers simply put it: "I haven't read it, I've lived it!" (Peer Researcher D). This article provides detailed discussion of the design and implementation of the peer research methodology including critical analysis of lessons learnt from the perspective of all of the stakeholders. Rather than prioritising one perspective or truth over another - those who have read it (academics) and those who have lived it (peer researchers) - we acknowledge the nuanced perspectives of the various stakeholders involved in peer research and advocate for a reflexive peer research approach that values the contribution of each team member and facilitates mutual dialogue and learning. The article concludes that, despite considerable challenges, peer research should become a routine consideration when designing research with young people who are leaving care.

\section{Peer Research in Care Leaver Studies}

Reflecting the development of the sociology of childhood and children's rights agenda over past decades, there is now an extensive body of literature exploring the involvement of children and young people in research (Christensen \& James, 2008; McLaughlin, 2005). Despite this focus on involving children and young people in research, there is still only a small body of literature on working with care leavers as peer researchers (Broad \& Saunders, 1998; 
Dixon et al., 2015; Lushey \& Munro, 2014; Torronen and Vornanen, 2014). These studies have shown how peer research can be an effective approach, however, they also emphasise the additional emotional, practical, financial and time investment it requires (Broad \& Saunders, 1998). In addition, Lushey and Munro (2014) reported variations in the quality of data collected and in the use of appropriate probing questions. Accordingly, they recommended the use of role play in peer researcher training and stressed the importance of recruiting young people who already possess the necessary transferrable skills.

Several UK studies have adopted the National Care Advisory Service (NCAS) model of involving care leavers in all aspects of the research process (Dixon et al., 2015; Lushey \& Munro, 2014; WMTD Catch 22 \& NCB, 2007). The most recent of these studies, the English Corporate Parenting Study (Dixon et al., 2015) trained and supported 36 peer researchers to develop interview guides, conduct interviews and assist with the analysis and presentation of the findings. A range of benefits of peer research were reported, including improved quality of data through enhanced rapport with participants and the development of peer researchers' employability skills and self-confidence. However, significant challenges were also reported; including ethical and fieldwork safety issues, highlighting the need for more intensive support for care experienced peer researchers.

Several international care leaver studies have also incorporated peer research approaches (Kelly et al., 2017; Torronen and Vornanen, 2014; Verweijen-Slamnescu \& Bowley, 2014). These studies found that respondents felt comfortable being interviewed by a peer in tune with their life experiences, peer researchers benefitted from learning new skills, and the studies gained from deeper insights into service user perspectives on how to improve the service system. However, major challenges were reported including the need for peer researchers to build their research skills over time and to manage their own care leaving experience alongside the peer researcher role (Torronen and Vornanen, 2014).

These previous care leaver studies suggest that peer research has added value but also highlight a wide range of challenges: resourcing, recruiting, managing ethical concerns, negotiating roles, and providing appropriate training and support. There are also concerns 
about the lack of evidence on the effectiveness of peer research based on robust evaluations of the approach (Barber et al., 2011; Staley et al., 2014). It is within this context that the peer research methodology reported here was developed and formally evaluated, highlighting the benefits and challenges for each of the project stakeholders: peer researchers, study participants, academic researchers and study partners.

\section{Overview of the YOLO Study}

The aim of the YOLO study was to examine the experiences of young people with mental health and/or intellectual disabilities who are leaving care. The peer research approach was part of the second stage of the study which involved semi-structured interviews with care leavers to explore their experiences of moving on from care and their views on how well services met their needs. An accessible version of the interview schedule was developed for participants with intellectual disabilities incorporating a visual map of the care leaving journey and pictorial images for key questions. Peer researchers carried out interviews at three separate points over an 18 month period with 31 care leavers aged 16-25 who were leaving a range of care settings including non-relative foster care, kinship care and residential care. The peer research phase of the study was formally evaluated by an academic who was independent from the research team (Dowling, 2016).

There were a number of reasons for adopting the peer research approach: to give expression within the methodology to the project's commitment to inclusion and social justice; to redress the imbalance in the power relationships between academic adult researchers and care leavers participating in the study; to utilise the personal experience and understanding of care leavers in framing research questions; to facilitate more open interviews through the rapport based on shared experience; and to incorporate service user perspectives in the analysis of data and recommendations for policy and service development.

Peer researchers were recruited via the study's main partner in the voluntary sector, VOYPIC (Voice of Young People in Care), local Health and Social Care Trusts and two Universities in Northern Ireland. A total of 12 young people were interviewed and 10 successful candidates 
then participated in an orientation session and a peer research workshop with an experienced peer researcher who had previously been in care.

Following these workshops and subsequent training, six applicants withdrew from the process either because of new personal, training or employment commitments or a realisation that the role was not what they expected. The final four peer researchers were all care experienced young people in their early twenties - two males and two females. Three of these young people had experience of higher education and the fourth was not engaged in education or employment. All four were living independently having left a range of care settings including kinship care, non-relative foster care and residential care. Within the group of peer researchers, there was prior experience of intellectual disabilities and mental health issues. All of the peer researchers completed a five day compulsory training programme to ensure they had the knowledge and skills required to fulfil the role. Peer researchers had opportunities to role play and practise problem solving issues that may arise during fieldwork. The topics covered were: study context and theoretical framework; research ethics; understanding disability, mental health and leaving care; and developing interview questions and skills. All members of the research team contributed to the training and several sessions were cofacilitated by service users and a care experienced researcher who shared tips on how to manage fieldwork and own care experience. During training, peer researchers drafted personal introductions to participants and co-produced the semi-structured interview schedules. Following training, peer researchers attended a final assessment workshop where they were observed role playing an interview using unseen scenarios and engaged in a feedback session with the academic researchers on their strengths and weaknesses in preparation for fieldwork.

A range of important practical arrangements and supports were then put in place to assist peer researchers in their role during fieldwork.

- $\quad$ Logistics. The academic researcher coordinated the interviews ensuring that the date, time and venue suited the participant, the peer researcher and the academic 
researcher. This alleviated the pressure on peer researchers and ensured that the study adhered to the planned timetable for fieldwork.

- $\quad$ Payment. Whilst peer researchers had not been paid during the mandatory training course, all peer researchers were paid for their time and expenses once fieldwork commenced to clearly acknowledge their contribution to the study.

- $\quad$ Transport, debriefing and informal support. Three of the four peer researchers who did not drive were driven to and from interviews by academic researchers which facilitated the development of close working relationships and provided an opportunity to process emotional responses to interviews and reflect on each experience of interviewing. The peer researcher who travelled independently met an academic researcher pre and post initial interviews for similar informal preparation and debriefing.

- $\quad$ Refresher Training. Refresher training $(n=4)$ and workshops $(n=4)$ provided further support for peer researchers to reflect on their experiences and analyse data in preparation for follow up interviews. Academic and peer researchers also attended a joint training day led by an external trainer on the use of the MAXQDA computer package for qualitative data analysis.

These structures and processes of support for the peer researchers were critical to the success of the study. They represented considerable additional investment in terms of cost, time and effort as could be anticipated from the existing literature. What became clearer however, and is not well documented in the literature, was the range of ways in which the different stakeholders experienced the challenges and benefits of the peer research process. These varying perspectives on the peer research experience will now be considered and a core theme highlighted: the importance of allowing flexible opportunities for mutual reflexive learning and co-production.

\section{Process of Co-production}


'It was good... the ones we did together, I learnt from her [the academic researcher]...

I kept having it in my head to ask [about mental health] but I wasn't sure about how to go about it... The way she phrased it was good...' (Peer Researcher A).

Other care leaver studies trained peer researchers to conduct interviews on their own or in pairs. Whatever the training provided, most of these studies reported a need for more practical and emotional support from the academic researcher than had been anticipated (Broad and Sanders, 1998; Dixon et al., 2015; Verweijen-Slamnescu \& Bowley, 2014). What developed in the YOLO study, through continuing the process of active co-production, was a more staggered approach to the interview phase.

During training it became clear that the peer researchers wanted to have an academic researcher with them for the first round of interviews not just to provide transport but also support during the interviews if needed. Peer researchers saw this as an opportunity for the academic researcher to observe and provide feedback on their interviewing to help build their confidence for interviewing alone. The academic researcher was also assured that sufficient quality data was collected by witnessing how well the peer researchers developed rapport with study participants and utilised their interviewing skills.

In order to ensure a clear role for both the academic and peer researchers in these early interviews, it was agreed that, at the beginning of first interviews, the academic researcher would check that the participant had full information about the study, consent forms were signed and audio recorders were working. The peer researcher then led the interview. The academic researcher on occasions assisted if the peer researcher indicated that they were unsure how to ask further questions about services or sensitive issues. The academic researcher also helped when unexpected issues arose during fieldwork; such as, the presence of a young child or other family members. By observing how the academic researcher dealt with these practical and ethical issues in the first round of interviews, peer researchers developed their skills and confidence for the later interviewing on their own: 
I felt that it was appropriate when the academic researcher was there... and that I was able to develop more with that support there, then I felt fine about the interviews that I did on my own' (Peer researcher B).

There were some aspects of the interview that peer researchers found more challenging such as, asking about mental health/disability issues or unfamiliar services. The peer researchers needed to build their confidence to say when they did not know about a service and ask the participant to provide further explanation. These were the types of issues peer researchers raised at reflection workshops during fieldwork where they sought advice and developed strategies to help them in future interviews. These workshops were also an important opportunity for peer researchers to receive positive feedback on their progress and the success of interviews already completed.

As the study progressed, peer researchers conducted more interviews on their own as they knew the study participants and felt more confident. However, in some cases, co-produced interviews continued, particularly when the presence of two researchers was ethically appropriate in terms of safety or support or practically important in terms of managing interviews in disruptive environments. Again, the roles of both academic researcher and peer researcher were clear and agreed in advance.

Peer researchers also co-produced the interview schedules as the study progressed by coanalysing transcripts of early interviews to develop appropriate questions for follow up interviews. The mid-point 'check in' interviews were mainly conducted by telephone to reduce costs and travel and then the final interviews were face-to-face, again usually held in the young person's home. This ongoing process of working in partnership with the peer researchers ensured interviews were addressing the broader research questions whilst being sensitive to each participant's situation and the peer researcher's style of interviewing:

'It helped because... it kept us involved and understanding the young person more before we went in to do the next interview... It meant that we stayed familiar with their story and helped us do the interviews' (Peer researcher C). 
This level of co-production requires the academic researcher to share control of the research process and work alongside peer researchers with an attitude of respect for their expertise and unique contribution to the research team:

'They [academics] treated us like we were staff on the same level... right from the start that makes such a difference... They didn't treat us any differently because we have care experience... It is nice to feel valued... that you are important to the project' (Peer Researcher B).

\section{Benefits and Challenges}

What should be clear from the detailed account of the design and its implementation are the demands it made on both the peer researchers and the academic researchers. However, it is important to recognise that it is not only those parties who stand both to be challenged and to benefit from the experience of co-producing research. As part of the evaluation, the views of each of these stakeholders were sought at key stages of the study. Research participants completed a one page questionnaire at the end of each interview to ascertain their perspectives on being interviewed by a peer and were given an opportunity to discuss their responses if they wished to elaborate. Peer researchers were interviewed individually and in focus groups. Academic researchers and VOYPIC staff also participated in focus groups and interviews at key phases of the study. Table 1 below summarises the benefits and challenges of the peer research method for each of these four stakeholders in the project.

Table 1: Benefits and challenges of peer research (adapted from Kelly et al., 2017a: 16)

\begin{tabular}{|c|c|c|}
\hline STAKEHOLDERS & BENEFITS & CHALLENGES \\
\hline $\begin{array}{l}\text { Study } \\
\text { Participants }\end{array}$ & $\begin{array}{l}\text { - Sensitive research approach } \\
\text { - More relaxed, informal } \\
\text { approach helping them to } \\
\text { share their stories } \\
\text { - Peer contact and access to } \\
\text { care experienced role models } \\
\text { - Motivation to stay engaged } \\
\text { - Signposting to support services }\end{array}$ & $\begin{array}{l}\text { - Being interviewed by a novice } \\
\text { researcher } \\
\text { - Knowing the peer researcher } \\
\text { - Dealing with differences in care } \\
\text { experience and educational level } \\
\text { - Understanding the boundaries of } \\
\text { peer researcher role }\end{array}$ \\
\hline
\end{tabular}




\begin{tabular}{|c|c|c|}
\hline $\begin{array}{l}\text { Peer } \\
\text { Researchers }\end{array}$ & $\begin{array}{l}\text { - Built confidence } \\
\text { - Acquired research skills } \\
\text { - Paid work experience in a } \\
\text { professional role } \\
\text { - Developed research skills } \\
\text { - Formed new friendships } \\
\text { - Re-framed own care } \\
\text { experience } \\
\text { - Influenced research, policy and } \\
\text { service development } \\
\text { - Informed future careers }\end{array}$ & $\begin{array}{l}\text { - Time management, cost and } \\
\text { transport } \\
\text { - Managing role boundaries } \\
\text { - Pace of study } \\
\text { - Learning new skills \& knowledge } \\
\text { of disability/ mental health issues } \\
\text { - Managing emotional involvement } \\
\text { - Dealing with ethical issues and } \\
\text { endings }\end{array}$ \\
\hline $\begin{array}{l}\text { Academic } \\
\text { Researchers }\end{array}$ & $\begin{array}{l}\text { - Greater rapport and empathy } \\
\text { - Enhanced motivation and } \\
\text { commitment to the study } \\
\text { - Insider insight during data } \\
\text { collection/analysis enhancing } \\
\text { study quality, authenticity and } \\
\text { robustness } \\
\text { - Assistance from peer } \\
\text { researchers at each stage of } \\
\text { the research process } \\
\text { - Deeper understanding of } \\
\text { participation including its } \\
\text { theoretical challenges }\end{array}$ & $\begin{array}{l}\text { - Added financial costs and time } \\
\text { required to train, support, } \\
\text { coordinate and involve peer } \\
\text { researchers } \\
\text { - Helping peer researchers to } \\
\text { manage their desire to advocate } \\
\text { and advise participants } \\
\text { - Retaining peer researchers and } \\
\text { replacing those who withdraw } \\
\text { - Being flexible in the study } \\
\text { approach }\end{array}$ \\
\hline Study Partners & $\begin{array}{l}\text { - Introduced more young people } \\
\text { to partner organisations } \\
\text { - Developed capacity to support } \\
\text { research and its impact on } \\
\text { policy and practice } \\
\text { - Added insight into care leaver } \\
\text { needs } \\
\text { - Authored publications } \\
\text { - Further expression to the value } \\
\text { of participation }\end{array}$ & $\begin{array}{l}\text { - Managing staff time commitment } \\
\text { to project } \\
\text { - Ensuring timely administration of } \\
\text { payments } \\
\text { - Recruiting and replacing peer } \\
\text { researchers } \\
\text { - Providing accessible formal } \\
\text { support for peer researchers }\end{array}$ \\
\hline
\end{tabular}

\section{Peer Researchers}

Based on the experience of previous peer research studies, many of the challenges encountered were expected and addressed in the training programme. Indeed, some of the challenges outlined in Table 1 are applicable to any research study employing new researchers to collect data, for example, the need for support and careful time management. However, some of the ordinary challenges of research are more acute for peer researchers. For example, there is an added dimension to managing emotional involvement and endings for care experienced peer researchers who are driven by a commitment to make a positive difference to the lives of other care leavers. Hearing the stories of other care leavers did reawaken issues for the peer researchers who often spoke of their own experience of care or 
trauma in debriefing after the interview. The peer researchers felt it was important that they had left care several years previously and had time to process their own care experience before engaging in interviews with others with similar experiences:

'In terms of it bringing up stuff for us... For me, it is in my past... I can speak about it without getting overly emotional... I think it is good to try to use your past to... help other people, but at the same time it depends on how raw things are for you' (Peer Researcher B).

Indeed, when asked what advice they would give to other peer researchers, they advised:

'Prioritise self-care.... recognise the impact of the work on your own emotions... and use supports on offer... empathy and strong emotions are ok' (Peer Researcher A). Whilst efforts were made to match peer researchers with participants who did not know them, there were situations where the peer researcher discovered on the day of interview that they knew the person through their own care experience or a connection with one of their close family members. In these cases, peer researchers could choose not to conduct the interview. However, there were a few cases where the peer researcher wished to proceed and, following disclosure of how they knew the young person, participants decided whether to proceed with the interview or re-schedule with an alternative interviewer. In all of these cases, participants agreed to be interviewed and indicated that the prior connection with the peer researcher had helped to facilitate their engagement in the interview. Whilst this worked well in these cases, the research team felt that these situations needed to be carefully managed to protect the privacy of both the peer researcher and the participant and to ensure they make an informed decision before they proceed with such an interview.

The level of rapport and empathy that quickly developed between peer researchers and participants was beneficial for the study but also made endings difficult. Some peer researchers expressed a desire to continue contact with participants to show ongoing interest in their lives or to offer mentorship. Peer researchers were concerned that they had developed a close rapport with young people to gather data and then left them alone with limited support. There was an empathic desire to help and, although ethical boundaries were not breached by 
peer researchers, some did feel they should be able to offer some ongoing support for young people:

'By the third interview, there were some I felt... like I had known them for years... and I came away thinking, 'I am not going to see them again, that's a bit sad'... There was one in particular... she had a lot of things going on... and she didn't have any friends... I would love to have kept in contact with her' (Peer Researcher A).

Peer researchers drew on the support from the academic researcher to manage endings. However, it could be argued that the design of peer research studies should allow and plan for a more personal approach to endings including an option for peer researchers to move on to a peer mentoring role, supported by a relevant organisation. Whilst there may be concerns about role confusion, the strict boundaries of the 'role' peer researchers occupy is not necessarily a concern to participants or peer researchers and, given the social isolation experienced by many care leavers participating in the study, it may actually be more ethically responsible to offer continued contact, as one peer researcher explained:

'Young people would not be concerned about the role, just more accepting of the fact that you were willing to stay and go beyond' (Peer Researcher D).

On a practical level, the peer researchers had limited incomes and were working on a sessional basis. They, therefore, had to manage other work or college commitments alongside the peer research role. It could be possible for future peer research projects to offer a parttime contracted research post for one or two peer researchers to avoid these pressures; although some of the young people preferred sessional work as it meant they could pursue ongoing studies or employment alongside the peer research role.

Despite these challenges, the peer research approach had a profoundly positive impact on the peer researchers. It was expected that peer researchers would acquire new research skills and benefit from work experience. What was not anticipated was the extent to which peer researchers would use the experience to re-frame their own care identities and future careers: 
'Sometimes you... think what happened was bad and you were in care... The study just made me realise how valuable my own experience is and how you can actually help other people through your own experience.... It has helped me realise that I have a lot to give and a lot to be proud of and I can make a difference' (Peer Researcher D).

The peer researchers also felt they had learnt a lot from listening to the stories of those they interviewed:

'You learn from them about how they cope in their lives and the different challenges they face, and that changes you too' (Peer Researcher B).

Indeed, one peer researcher felt that involvement in the study gave her the confidence to more openly share her care identity and another was motivated to pursue further research experience:

'I always tried to ignore my experience... but now I have embraced it... It is helping me shape my own journey - where I came from and where I am at now' (Peer researcher A).

Young people also described how the growth in their confidence had impacted on other areas of their lives:

‘Before I would have been shy, I wouldn't really talk in case it came out all wrong, and now I would be the first one to do the talking. This project has been a big part of helping me get my confidence' (Peer Researcher D).

Peer researchers also reported an increased understanding of disability which changed their approach to daily encounters with disabled people:

'I know how to approach them [disabled people], to not belittle them, not feel sorry for them cause they are just normal people like me and you, so... just seeing the person' (Peer Researcher C).

Research Participants 
A total of 26 young people interviewed by a peer researcher completed a one page questionnaire after their first interview on their views on peer research. All of these respondents felt it was important that peer researchers interviewed care leavers. All except one agreed that it was easier to talk to a peer researcher than it would have been to an academic researcher and that the peer researcher was good at interviewing them. Participants acknowledged how the informal interviewing style of peer researchers helped them to engage in the interview:

'It's definitely been beneficial... to talk to... somebody that actually cares about what I'm saying... It was good to get it out... and you're easy going too, you're not forceful of what you're asking' (Study Participant).

All except two indicated that they would share more with a peer researcher than an academic researcher and when given the choice, they would prefer a peer researcher to interview them. One of the two participants who were unsure felt they could not comment because they had no comparative experience of being interviewed by an academic researcher and the other felt that the peer researcher could be upset by their story.

Peer researchers recalled how participants remarked on how their own care experience and non-judgemental approach enabled a greater level of openness in the interview:

'There can be feelings of embarrassment and a stigma about being in care and it can be difficult to talk about it... They can open up a lot easier 'cause... they know that we could empathise... I think even my facial expression and body language, like its authentic, and you can tell the difference if somebody really gets something and really empathises, and somebody who is trying to but they can't really 'cause they haven't been in that sort of situation' (Peer Researcher C).

Research participants also made similar statements at the end of interviews when asked their views on being interviewed by the peer researcher:

'I think (the peer researcher) has been through the same system as I have... They have been a joy to talk to. Finally, someone who doesn't judge me' (Study Participant). 
By the time of the third interview, 18 research participants completed the same feedback questionnaire and all agreed that peer researchers were easy to talk to and were good at interviewing them. All respondents indicated that they would share more with the peer researcher and all except one indicated a preference for the peer research approach. This young person explained that there may be cases where a peer interviewer is not appropriate and this was true for some cases in our study.

The feedback from participants indicated that they felt empowered by sharing their story with the peer researchers and the opportunity to potentially influence future policy and practice impacting on the lives of care leavers, as one participant explained:

'I really hope social workers listen to it... because at the end of the day we're the only ones that really know' (Study Participant).

Finally, the research participants benefitted from meeting the peer researchers as they showed them that there are a range of future opportunities for care leavers and could be seen as positive role models who were doing well in their post-care young adult lives, engaged in employment or further education. Indeed, the peer researchers commented on their own lack of opportunity to meet other care experienced young people and the important opportunity they had to show participants the positivity in their own post-care lives:

'When I was growing up in care I literally did not know one other child who was looked after... Meeting us, you would hope that would give a sense of encouragement that things can change for them for the better' (Peer Researcher A).

\section{Academic Researchers}

The main challenges for the academic researchers were practical in terms of the added cost and time required to recruit, train and support peer researchers. A high level of organisational and management skill is also required to coordinate the wider research team and ensure peer researchers have full opportunity to participate at all stages of the project. These practical challenges, however, were far outweighed by the benefits of the peer research approach. The involvement of peer researchers helped the academic researchers to: improve the design of 
the interview schedules and approach; deliver a well-paced and empathic style of interviewing which encouraged participants to stay connected with the project for multiple interviews over time; enhance the authenticity of the analysis of interview data; and refine the recommendations for policy and practice. On joint interview visits, the academic researchers observed how peer researchers quickly developed a close rapport with participants and adopted an empathic approach that was responsive to the needs of each young person. Interestingly, participants also showed an empathy for peer researchers when they were feeling nervous or lost their flow of questioning in first interviews, often offering encouragement and reassurance to the peer researchers which demonstrated a mutual respect and support for each other that helped to break down power differentials and build a strong rapport. Based on their shared experiences, the academic researchers felt that the peer researchers were able to break down barriers that would most likely have remained if participants were only interviewed by academic researchers who were not care experienced:

'We haven't walked the walk either, we haven't been in care... There is the barrier between professionals and young people... Whereas when talking to the peer researchers all those barriers just weren't there' (Academic Researcher).

In situations where participants seemed anxious or found it difficult to answer interview questions, the peer researchers offered breaks to talk informally first, quickly re-phrased questions in terminology the young people were more familiar with, and used communication aids to create an unpressured interview that helped each young person to share their story and enhanced the range and depth of data collected. One of the academic researchers recalled one such interview experience:

'The young person was very nervous and anxious... The interview nearly didn't happen if it hadn't been for the peer researcher... who said, 'Why don't we go outside, we can have a smoke, if you want we can do the interview outside, we can do it very informally, we don't even need the script, I know the kind of things that we are looking for to talk about'... She decided she wanted to do the interview... It was very much down to the 
peer researcher's interpersonal skills, giving a range of options to help put her at ease and to build rapport and sort of empowering her' (Academic Researcher).

The ability of peer researchers to collect necessary data whilst facilitating an informal relaxed interview approach was key to the success of the project and retention of participants who reported that, over their time in care, they had become tired of recounting their personal histories in formal interviews and assessments with various professionals. The peer researchers made it clear to participants that they were involved in the study because they wanted the project to make a difference and they would work closely with the rest of the research team to ensure the stories of care leavers would influence future leaving care policy and practice.

Rather than viewing their involvement in the study as a 'job', peer researchers had a strong commitment to the successful completion of the project, working at short notice often outside usual working hours. The peer research role also went beyond conducting interviews to assisting with data analysis and delivering impactful presentations of research findings to a range of audiences. At times, the integrity and enthusiasm of the peer researchers was a driving force for the academic researchers and project partners. The reflexive approach to the peer research process also stimulated dialogue between the peer researchers and academic researchers that drew on personal and professional expertise to inform a deeper, critical analysis of data that helped to build strong recommendations for policy and practice.

\section{Key Project Partner}

The voluntary organisation VOYPIC played a key role in terms of assisting with the recruitment and training of the peer researchers and providing practical support for them throughout the study. VOYPIC also brought fresh ideas on participatory training and constructive approaches to feedback to young people during recruitment, training and refresher workshops. As one of the research team stated: 
'VOYPIC played such an important part in terms of keeping that momentum going with peer researchers... asking the right questions or giving them a bit of feedback externally which was very important for them' (Academic Researcher).

The involvement of a partner organisation with expertise in working with care leavers also added credibility and support that encourage more young people to consider the peer research role and led to more powerful impact from the study.

There were also benefits for the partner organisation including the experience of being involved in a research study and building longer-term working relationships with academics and peer researchers. The peer researchers contributed to other VOYPIC activities beyond the study which widened the range of young people involved in their organisation and gave further expression to VOYPIC's core value of participation. Indeed, one peer researcher continued to work for the organisation on completion of the research study showing the longerterm benefits of a partnership approach for all project stakeholders.

\section{Discussion}

Overall, whilst adopting a peer research approach requires additional time and effort, the added ethical and methodological strengths alongside the personal and professional benefits of peer research, make a compelling case for involving care experienced young people in peer research (Kelly et al., 2017a). However, peer research needs to be carefully and flexibly planned, supported and resourced. Anyone considering commissioning or undertaking a peer research project with care leavers should consider the following points.

- Be clear about the rationale for a peer research approach in terms of collecting quality data to address core research questions, engagement with study participants, commitment to ethical principles of inclusion and participation, and consideration of underpinning theory.

- Plan from the very outset the allocation of additional costs and time required to support the peer research approach. 
- Carefully consider recruitment processes including the size of the peer research team, strategies to replace those who withdraw early from the study and payment for time. Explain clearly the level of commitment expected, the demands and boundaries of the role and the skills and time required.

- Collaborate with voluntary or community organisations who have experience of supporting care leavers and can bring expertise on participatory practice with young people.

- Consider the care journey of the peer researcher including their ability to cope with the emotional demands of the research; and provide ongoing practical and emotional support as fieldwork progresses. For some young people, informal support, debriefing and reflective workshops will be sufficient whilst others may require formal professional support that should be in place from the outset.

- Provide comprehensive training that is mandatory to prepare peer researchers for the role and develop solid working relationships as a research team. As the study progresses, provide reflective workshops and refresher training to facilitate shared learning, re-negotiation of roles and ongoing skills development.

- Involve peer researchers in all stages of the study. We have found that involving peer researchers throughout the research process recognises the expertise and insight they bring to each stage of the study and ensures ongoing co-production that improves the authenticity of the analysis of data and presentation of findings and recommendations.

- Adopt a reflexive approach that provides varying opportunities for co-production to engage in critical dialogue and share learning between academic and peer researchers and provide support for peer researchers when needed. Strong, open channels of communication helps to develop different modes of co-production as the study progresses. 
- Prepare peer researchers for making sensitive and supportive endings and explore the potential for peer researchers to adopt new roles with partnering organisations at the end of the study, for example, as peer mentors or participation workers.

\section{Conclusion}

Research design must always be dictated by aim and purpose and will also be influenced by the availability of funding, staffing and time. The YOLO experience suggests that, despite the considerable investment required and potential challenges, the benefits of peer research in advancing the agenda of co-production within care leaving research are such that it should become a routine consideration when designing research on care leaving. Peer research was found to be a methodologically sound, ethical and political approach to research with care leavers. It contributed significantly to the way in which the study was carried out, its findings and its recommendations. However, a peer research study must be well planned, resourced, supported and reflexive, with careful consideration of ethics and practicalities. There are added challenges when adopting a peer research approach with care leavers who have their own complex care histories. Rising to these challenges, however, can strengthen the research and lead to a powerful experience of co-produced knowledge for all stakeholders that adds much value to this field of study.

\section{Funding}

This work was supported by the Public Health Agency's Health and Social Care Research and Development Division who funded the research study.

\section{References}

Berger, R. (2015) Now I see it, now I don't: Researcher's position and reflexivity in qualitative research, Qualitative Research, 15 (2), pp 219-234.

Boxall, K. \& Beresford, P. (2013) Service user research in social work and disability studies in the United Kingdom, Disability \& Society, 28 (5), 587-600. 
Broad, B. \& Saunders, L. (1998) Involving young people leaving care as peer researchers in a health research project: a learning experience. Research, Policy and Planning, 16, (1), 1-9. Christensen, P. \& James, A. (2008) Research with Children: Perspectives and Practices. London: Routledge.

D’Cruz, H. \& Gillingham, P. (2017) Participatory research ideals and practice experience: Reflections and analysis, Journal of Social Work, 17(4), pp 434-452.

Dixon, J., Lee, J., Stein, M., Guhirwa, H., Bowley, S. \& Catch 22 Peer Researchers (2015) Corporate Parenting for Young People in Care: Making the difference? (London: Catch22).

Duffy, J., Gillen, P., Agnew, C., Casson, K., Davidson, G., McGlone, A., \& McKeever, B. (2016). Personal and Public Involvement (PPI) and its impact - Monitoring, measuring and evaluating the impact of PPI in Health and Social Care in Northern Ireland. Belfast: Public Health Agency.

Holland, S., Ronold, E., Ross, N.J. \& Hillman, A. (2f010) 'Power, agency and participatory agendas: A critical exploration of young people's engagement in participative qualitative research', Childhood, 17, 360.

Kelly, B., McShane, T., Davidson, G., Pinkerton, J., Gilligan, E. \& Webb, P. (2016)

Transitions and outcomes for care leavers with mental health and/or intellectual disabilities:

Final report. Belfast: QUB. Available at: http://www.research.hscni.net/bamfordimplementation-commissioned-call-portfolio Kelly, B, Dixon, J \& Incarnato, M (2017) 'Peer Research with Young People Leaving Care: Reflections from Research in England, Northern Ireland and Argentina' In Mendes, P. \& Snow, P. (Eds) Young people Transitioning from care: International research, policy and practice. London: Palgrave Macmillan, pp. 221-240.

Kelly, B. Friel, S., Smith, D., Pinkerton, J., McShane, T. \& Gilligan, E. (2017a) More than we expected! A guide to peer research with young people. Belfast: QUB.

Lushey, C. \& Munro, E. (2014) 'Peer research methodology: an effective method for obtaining young people's perspectives on transitions from care to adulthood?' Qualitative Social Work, 14(4), 522-537. 
McLaughlin, H. (2005) Young service users as co-researchers: Methodological problems and possibilities, Qualitative Social Work, 4(2): 211-228.

Smith, R., Monaghan, M. \& Broad, B. (2002) Involving young people as co-researchers: Facing up to methodological issues, Qualitative Social Work, 1, 191-207. Tangvald-Pedersen, O. \& Bongaardt, R. (2016) Towards a tinkering participatory research method in mental health, Scandanavian Journal of Disability Research, 19(1), pp. 7-17. Torronen, M. \& Vornanen, R. (2014) Young people leaving care: Participatory research to improve child welfare practices and the rights of children and young people. Australian Social Work, 67 (1), 135-150.

Verweijen-Slamnescu, R. \& Bowley, S. (2014) ‘Empowering young care leavers through peer research' in T. Stern (ed.), Action Research, Innovation and Change: International perspectives across disciplines (Oxon: Routledge), pp. 89-100.

WMTD Catch22 \& National Children's Bureau (2007) What Makes the Difference? London: WMTD/Catch22 \& NCB. 